\title{
Estrutura e diversidade da regeneração florestal na nascente do Córrego São Pedro, Juiz de Fora, MG
}

Kátia Rotmeister ${ }^{1}$

Diego Raymundo²

José Hugo Campos Ribeiro ${ }^{3}$

Cassiano Ribeiro da Fonseca ${ }^{4}$

Vinícius Campos Almeida 5

Fabrício Alvim Carvalho ${ }^{6}$

\section{Resumo}

Este trabalho descreve a composição florística, a estrutura do estrato regenerante arbóreo de um trecho de floresta secundária na nascente do Córrego São Pedro, localizado na área rural do município de Juiz de Fora, Minas Gerais, Brasil. 0 manancial foi escolhido devido à sua importância como recurso hídrico pela sua condição de corredor ecológico e por se tratar de uma Área de Preservação Permanente - APP. Em um trecho que compreende 700 metros, a partir da nascente, foram alocadas 25 parcelas de $5 \times 5 \mathrm{~m}$ e amostrados todos os indivíduos arbóreos com o diâmetro à altura do peito (DAP) $\leq 5 \mathrm{~cm}$ e altura $>1 \mathrm{~m}$, totalizando 983 indivíduos pertencentes a 42 espécies. Houve predominância de espécies de estágios sucessionais iniciais. Foi observada, também, uma elevada dominância ecológica exercida principalmente pela alta densidade de Tibouchina granulosa $(\mathrm{VI}=19,2 \%)$. 0 valor do índice de diversidade de espécies de Shannon $\left(H^{\prime}=2,81\right.$ nats.ind ${ }^{-1}$ ) foi inferior aos valores encontrados em fragmentos florestais na região. 0 fragmento de mata ciliar é pequeno e isolado, entretanto, apresenta considerável diferenciação no arranjo de espécies, o que demonstra a heterogeneidade característica das florestas tropicais. Ainda que seja um fragmento pequeno, dentro de uma matriz altamente impactada, possui relevante função ecológica na paisagem na qual está inserido.

Palavras-chave: Mata Atlântica. Fitossociologia. Restauração ecológica. Corredor ecológico. Mata ciliar.

\section{Introdução}

A Floresta Atlântica possui a maior concentração populacional do Brasil. Sua ocupação faz os recursos hídricos sofrerem pressões cada vez maiores. A destruição das florestas que margeiam cursos d'água contribui para a diminuição da vazão (DEAN, 2007) e o resultado do desmatamento vem acompanhado por um conjunto de problemas ambientais, que vai desde a extinção de espécies da fauna e flora até a escassez

\footnotetext{
1 Universidade Federal de Juiz de Fora, Programa de Pós-graduação em Ecologia, mestranda em Ecologia. Juiz de Fora, Minas Gerais, Brasil.katia.rotmeister@uol.com.br

2 Universidade Federal de Juiz de Fora, Laboratório de Ecologia Vegetal, Departamento de Botânica, graduando em Ciências Biológicas. Juiz de Fora, Minas Gerais, Brasil. diegoraynascimento@gmail.com

3 Universidade Federal de Juiz de Fora, Programa de Pós-graduação em Ecologia, doutorando em Ecologia. Juiz de Fora, Minas Gerais, Brasil.jhugocampos@gmail.com

4 Universidade Federal de Juiz de Fora, Programa de Pós-graduação em Ecologia, doutorando em Ecologia. Juiz de Fora, Minas Gerais, Brasil. cassianoribeirofonseca@gmail.com

5 Universidade Federal de Juiz de Fora, Programa de Pós-graduação em Ecologia, doutorando em Ecologia. Juiz de Fora, Minas Gerais, Brasil.vinacampos@gmail.com

6 Universidade Federal de Juiz de Fora, Laboratório de Ecologia Vegetal, Departamento de Botânica, professor do Departamento de Botânica. Juiz de Fora, Minas Gerais, Brasil. fabricio.alvim@gmail.com
} 
de água, assoreamento de cursos d'água, erosões e mudanças no micro e macroclima (MARTINS, 2001).

No município de Juiz de Fora, verifica-se a continuidade das modificações impostas às formações florestais para dar lugar à expansão imobiliária e a construção de rodovias para suprir as necessidades que vêm acompanhadas do crescimento demográfico e acabam por destruir os remanescentes florestais e hídricos da região (MACHADO, 2010).

As formações florestais, associadas a cursos d'água de diferentes nascentes, córregos e rios, são de enorme importância, pois desempenham um fator essencial na manutenção da integridade dos ecossistemas onde ocorrem. Representam, pois, áreas indispensáveis para a preservação da qualidade da água, exercendo a função de filtro, que minimizam o assoreamento dos corpos d'água, razões pelas quais são protegidas pela legislação florestal brasileira (BRASIL, 2012). Essas formações também auxiliam na preservação da biodiversidade, formando corredores de fluxo gênico e mantendo a dinâmica hidrológica dos rios e dos corredores ecológicos (RODRIGUES, 2009).

De acordo com Felfili (1995), Rodrigues (2009) e Martins (2001), as formações florestais associadas a cursos d'água deveriam ter prioridade em termos ecológicos de alocação de recursos para pesquisas, uma vez que são elementos indispensáveis para a manutenção do funcionamento hidrológico da microbacia, assim como da estabilidade do ecossistema aquático e de valores ecológicos da paisagem.

Estudos fitossociológicos são fundamentais para a recuperação ou preservação de qualquer remanescente florestal e principalmente de corpos hídricos (FELFILI, 1996; FELFILI 2003), tornando-se o ponto de partida para a preservação da diversidade e recuperação de corpos d'água. Porém, a maioria dos estudos é focada no componente arbóreo não se levando em consideração o estrato regenerativo. Análises de regeneração fornecem informações fundamentais sobre a dinâmica de espécies no ambiente (SEITZ, 1988) e são de suma importância para o conhecimento do futuro da comunidade, assim como para estratégias de recuperação de áreas degradadas (CARVALHO, 1982).

A recuperação das florestas associadas a cursos d'água contribui de forma contundente para o aumento da capacidade de armazenamento da água em toda microbacia, o que é fator decisivo para o aumento e manutenção da vazão na estação seca do ano (RODRIGUES, 2009).

A área de estudo desta pesquisa vem sendo impactada em seu entorno por vários empreendimentos, principalmente condomínios residenciais e loteamentos, que suprimem a vegetação e dificultam o fluxo gênico das espécies. 0 trecho florestal, objeto deste estudo, é uma parte importante do corredor ecológico dentro da matriz em que está inserido. Sua recuperação e manutenção são imprescindíveis para as dinâmicas ecológicas presentes.

O presente estudo tem por objetivo avaliar a composição e a estrutura do estrato regenerativo de um fragmento de floresta estacional semidecidual, em estágio secundário de sucessão, localizado na nascente do Córrego São Pedro, em Juiz de Fora, Minas Gerais.

\section{Material e métodos}

O trecho florestal está localizado na área da nascente do Córrego São Pedro pertencente à zona rural de Juiz de Fora (coordenadas da nascente $21^{\circ} 47^{\prime} 19,80^{\prime \prime}$ S, 4326'39,22"O). A área possui aproximadamente 2,5 hectares e o fragmento de mata ciliar do estudo situa-se no limiar entre as áreas das sub-bacias do córrego São Pedro e do Ribeirão da Conceição, limítrofes das bacias do Rio Paraibuna e do Peixe. Possui relevo geomorfológico denominado como Mar de Morros, caracterizado por ser repleto de colinas e vales com altitudes que variam de 600 a 900 m (PMJF, 2011).

A altitude do local de estudo varia de 800 a $860 \mathrm{~m}$, e a nascente localiza-se no ponto mais alto. Foi selecionada para o estudo uma faixa ciliar de aproximadamente $700 \mathrm{~m}$ de extensão a partir 
da nascente, com largura de 20 a $50 \mathrm{~m}$ em ambas as margens.

A vegetação do local é caracterizada como floresta secundária em estágio inicial de regeneração natural, segundo critérios da Resolução CONAMA 392/2007 (CONAMA, 2007), integrando a fisionomia de Floresta Estacional Semidecidual Montana (IBGE, 2012). A vegetação florestal é resultante da regeneração natural após abandono de pastagem há cerca de 10 anos. Durante o processo de regeneração, o trecho vem sofrendo constantes perturbações antrópicas, principalmente queimadas e pisoteio de gado, influenciando na cobertura vegetal do local que é incipiente e de pequeno porte.

O clima é do tipo Cwa (subtropical de altitude), segundo classificação de Köppen (KOTTEK et al., 2006), e apresenta duas estações definidas, verão - primavera, com temperaturas mais elevadas e maior precipitação pluviométrica (outubro a abril), e outono - inverno, mais fria e com menor precipitação (maio a setembro) (PMJF, 2011). A pluviosidade média anual é próxima a 1.500mm, com maiores índices no mês de janeiro ( $\sim 300 \mathrm{~mm})$, enquanto a média térmica anual oscila em torno de $18,9^{\circ} \mathrm{C}$ (PMJF, 2011).

Localização da área de estudo

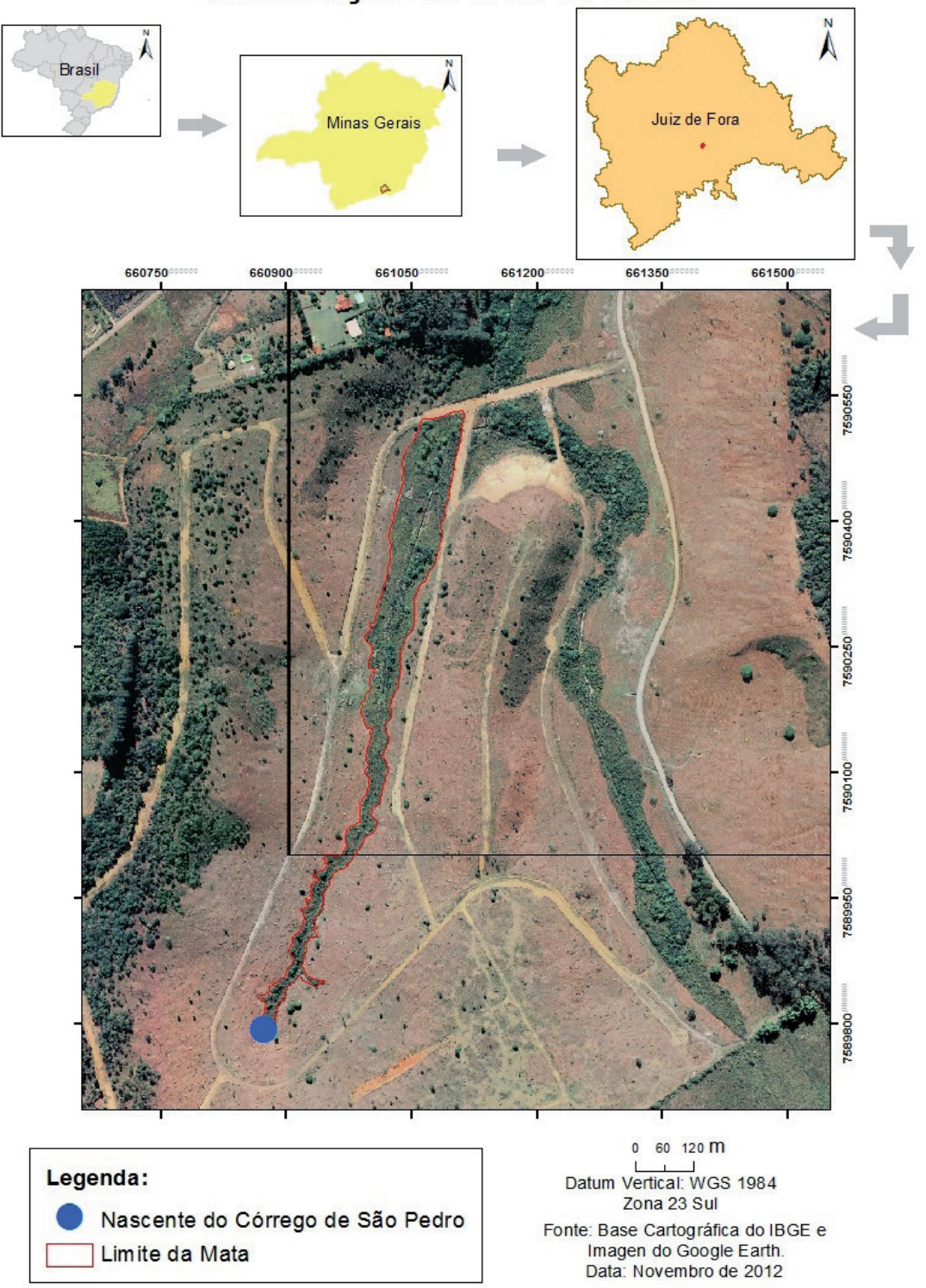

Figura1. Localização geográfica e limites fisicos da área de estudo, no município de Juiz de Fora, MG, Brasil. Fonte da imagem: Goog/e Earth-mapas. 


\section{Amostragem da vegetação}

Para a amostragem do fragmento florestal, cerca de 700 metros ao longo do córrego a partir da nascente foram delimitados como universo amostral e gradeados em parcelas de $5 \times 5 \mathrm{~m}$ para o sorteio das unidades amostrais. Em seguida, foi realizado o sorteio das 25 parcelas distribuídas aleatoriamente no fragmento, critério embasado em FELFILI et al. (2005). A coleta de dados foi realizada nos meses de julho, agosto e setembro de 2012.

Nas parcelas do fragmento florestal analisado, todos os indivíduos maiores que um metro e DAP (diâmetro a altura do peito) $\leq 5 \mathrm{~cm}$ foram mensurados quanto ao DAS (diâmetro à altura da base) e à altura (FELFILI et al., 2005). Os perfilhos foram considerados como indivíduos (fustes) nas análises (FELFILI et al. , 2005), uma vez que se comportam dessa maneira no ambiente, disputando os mesmos recursos. A medição do diâmetro foi feita com um paquímetro, e a altura, com o auxílio de uma vara graduada. O material botânico coletado foi depositado na coleção dendrológica do Laboratório de Ecologia Vegetal (Departamento de Botânica, UFJF) para identificação no Herbário Leopoldo Krieger (CESJ). A sinonímia das espécies foi conferida na página da Flora do Brasil (FLORA DO BRASIL, 2014) e a classificação das famílias botânicas seguiu o Angiosperm Phylogeny Group (APG III, 2009).

\section{Análises dos dados}

Para a descrição quantitativa da comunidade arbórea, foram calculados os parâmetros fitossociológicos das espécies: riqueza (número) de espécies (S), número de indivíduos (DA), área basal total e individual ( $A B t$ e $A B i$ ), frequência absoluta e relativa ( $F A$ e $F R$ ), densidade relativa (DR), dominância relativa (DoR) e valor de importância (VI = soma FR, DR e DoR) (KENT; COKER, 1992).

Para a análise de diversidade, foi utilizado o índice de Shannon (H') (MAGURRAN, 2004). 0 índice de equabilidade de Pielou (J), baseado em H', foi utilizado para estimativa da uniformidade da comunidade. As análises foram realizadas no software PAST v. 2.12 (HAMMER, 2001).

\section{Grupos ecológicos}

As espécies foram enquadradas em grupos sucessionais, segundo o banco de dados do inventário florestal de Minas Gerais (OLIVEIRA-FILHO e SCOLFORO, 2008), sendo classificadas de acordo com suas características ecológicas e sucessionais, tendo como principal fator de inclusão nas categorias a quantidade de luz disponível para seu desenvolvimento: P (pioneiras); SI (secundárias iniciais); ST (secundárias tardias) e CL (clímax). Em decorrência da alta divergência das informações na literatura, as espécies foram classificadas em Pioneiras, Não Pioneiras e Não Classificadas, quando não foram obtidas informações.

Segundo VAN DER PIJL (1982), as espécies foram classificadas de acordo com a estratégia de dispersão e seus frutos e sementes, quais sejam: anemocórica, quando o propágulo é dotado de estruturas que facilitam o transporte de vento; autocórica, quando apresenta mecanismos próprios para o lançamento dos frutos ou sementes; zoocórica, quando a dispersão é realizada por animais. 


\section{Resultados e discussão}

\section{Composição florística e fitossociologia}

Foram registrados 983 indivíduos na área amostrada, distribuídos em 18 famílias, 31 gêneros e 42 espécies (Tabela 1). Dentre as famílias de maior densidade, estão Melastomataceae (23,7\%), Lauraceae (13,3\%), Myrtaceae (12,5\%), Euphorbiaceae (10,9\%) e Salicaceae (10,6\%).

A Tabela 1 apresenta a estrutura fitossociológica da comunidade, na qual se observa uma concentração do VI em um pequeno conjunto de espécies, sendo elas: Tibouchina granulosa (Desr.) Cogn. (19,2\%), Casearia sylvestris Sw. (9,8\%), Nectandra oppositifolia Nees \& Mart. (8,4\%), Sapium glandulosum (L.) Morong (6,9\%) e Myrcia splendens (Sw.) DC. (6,7\%).

Os padrões florísticos encontrados, com elevada representatividade na riqueza das famílias Melastomataceae, Primulaceae, Lauraceae e Euphorbiaceae, estão de acordo com os descritos por Oliveira-Filho (2006) para o domínio da floresta estacional semidecidual Montana na Região Sudeste do Brasil e da Zona da Mata de Minas Gerais. Mesmo se tratando de um fragmento florestal isolado de mata ciliar em um ambiente rural degradado e com aproximadamente 20 anos de regeneração natural e frequentes queimadas no local possui uma representatividade arbórea que corresponde àquela descrita por Oliveira-Filho (2006).

Entre as espécies mais importantes da comunidade regenerante, a que obteve o VI mais alto foi Tibouchina granulosa, uma pioneira de dispersão anemocórica, perenifólia, heliófita e característica de regiões úmidas. Obteve o VI mais alto devido à sua contribuição na densidade, com 22,9\% do total. Essa espécie é muito encontrada na Serra do Mar, quase sempre em mata secundária, e algumas vezes é a espécie que apresenta dominância nesses locais (LORENZI, 2008). Foi encontrada em 14 parcelas, o que demonstra boa capacidade de dispersão pela área, com caráter generalista em termos de nicho. Pelo número de indivíduos e frequência nas parcelas, observa-se uma tendência de dominância da espécie futuramente. Vale a pena ressaltar que $T$. granulosa representa uma das poucas espécies de dispersão anemocórica na área de estudo, o que pode ajudar a explicar sua frequência elevada entre as parcelas, pela maior facilidade da dispersão de suas sementes pelo vento, em uma área florestal relativamente aberta.

Com o segundo maior VI está Casearia sy/vestris, uma nativa, que se desenvolve em ambientes sombreados ou semissombreados, como no interior de florestas densas. Essa espécie é higrófita e ocorre com grande frequência em formações secundárias (LORENZI, 2008). Apesar de ser uma espécie menos frequente em florestas estacionais semideciduais, foi encontrada em praticamente metade das parcelas amostradas, demonstrando boa capacidade de dispersão na área.

A espécie de terceiro maior VI foi Nectandra oppositifolia, uma pioneira de dispersão zoocórica, perenifólia, heliófita, sem preferência definida por condições físicas do solo. Presente em matas ciliares de solos úmidos até solos de rápida drenagem em morros, seu desenvolvimento ocorre preferencialmente nas florestas secundárias menos densas (LORENZI, 2008). Foi encontrada em 15 das 25 parcelas amostradas, mostrando boa capacidade de dispersão pela área e com caráter generalista em termos de nicho. 
Tabela 1. Parâmetros fitossociológicos das espécies regenerantes amostradas no fragmento florestal no Parque Tecnológico da Universidade Federal de Juiz de Fora, Juiz de Fora, Minas Gerais, Brasil. Espécies ordenadas de forma decrescente segundo o VI. Siglas: GS: grupo sucessional (PI: pioneira; NPi: Não Pioneira e NC: não classificada); SD: síndrome de dispersão (Z: zoocórica; An: anemocórica; Au: autocórica e NC: Não Classificada); DA: densidade absoluta (ha-1); $A B$ : área basal $\left(\mathrm{cm}^{2}\right.$. ha-1); DR: densidade relativa; DoR: dominância relativa; FR: frequência relativa; VI: valor de importância.

\begin{tabular}{|c|c|c|c|c|c|c|c|c|c|c|c|}
\hline Espécie & Família & GS & SD & $\mathrm{DA}$ & AB & FA & DR & DoR & FR & VI & VI\% \\
\hline Tibouchina granulosa Cogn & Melastomataceae & $\mathrm{P}$ & $A n$ & 225 & 998,16 & 14 & 22,89 & 27,79 & 7 & 57,68 & 19,23 \\
\hline Casearia sylvestris Sw. & Salicaceae & $\mathrm{P}$ & Z & 112 & 435,64 & 12 & 11,39 & 12,13 & 6 & 29,52 & 9,84 \\
\hline Nectandra oppositifolia Nees & Lauraceae & $\mathrm{P}$ & Z & 75 & 361,10 & 15 & 7,63 & 10,05 & 7,5 & 25,18 & 8,39 \\
\hline Sapium glandulosum (L.) Morong & Euphorbiaceae & $P$ & Z & 46 & 266,75 & 17 & 4,68 & 7,43 & 8,5 & 20,61 & 6,87 \\
\hline Myrcia splendens (Sw.) DC. & Myrtaceae & $P$ & Z & 97 & 99,71 & 15 & 9,87 & 2,78 & 7,5 & 20,14 & 6,71 \\
\hline Myrsine Guianensis Aubl. & Primulaceae & $\mathrm{P}$ & Z & 83 & 299,31 & 3 & 8,44 & 8,33 & 1,5 & 18,28 & 6,09 \\
\hline Myrsine coriacea (Sw.) R.Br & Primulaceae & $\mathrm{P}$ & Z & 9 & 69,66 & 19 & 0,92 & 1,94 & 9,5 & 12,35 & 4,12 \\
\hline Croton urucurana Baill. & Euphorbiaceae & $\mathrm{P}$ & $\mathrm{Au}$ & 40 & 194,28 & 5 & 4,07 & 5,41 & 2,5 & 11,98 & 3,99 \\
\hline Beilschmiedia sp1 & Lauraceae & NP & Z & 40 & 94,88 & 10 & 4,07 & 2,64 & 5 & 11,71 & 3,90 \\
\hline Alchornea triplinervia (Spreng.) Müll.Arg. & Euphorbiaceae & $\mathrm{P}$ & Z & 23 & 120,38 & 9 & 2,34 & 3,35 & 4,5 & 10,19 & 3,40 \\
\hline Aegiphila integrifolia (Jacq.) Moldenke & Verbenaceae & $\mathrm{P}$ & Z & 23 & 128,90 & 7 & 2,34 & 3,59 & 3,5 & 9,43 & 3,14 \\
\hline Machaerium hirtum (Vell.) Stellfeld & Fabaceae & $\mathrm{P}$ & An & 22 & 100,22 & 7 & 2,24 & 2,79 & 3,5 & 8,53 & 2,84 \\
\hline Psychotria carthagenensis Jacq. & Rubiaceae & NP & Z & 16 & 37,11 & 8 & 1,63 & 1,03 & 4 & 6,66 & 2,22 \\
\hline Psidium cattleianum Sabine & Myrtaceae & $\mathrm{P}$ & Z & 25 & 22,00 & 6 & 2,54 & 0,61 & 3 & 6,16 & 2,05 \\
\hline Miconia sp1 & Melastomataceae & NC & Z & 22 & 26,93 & 6 & 2,24 & 0,75 & 3 & 5,99 & 2,00 \\
\hline Piptocarpha angustifolia Dusén ex Malme & Asteraceae & $\mathrm{P}$ & An & 13 & 73,46 & 5 & 1,32 & 2,05 & 2,5 & 5,87 & 1,96 \\
\hline Spondias mombin L. & Anacardiaceae & NP & Z & 13 & 45,33 & 4 & 1,32 & 1,26 & 2 & 4,58 & 1,53 \\
\hline Virola gardneri (A.DC.) Warb. [realia] & Myristicaceae & NP & Z & 13 & 28,52 & 3 & 1,32 & 0,79 & 1,5 & 3,62 & 1,21 \\
\hline Piptocarpha cf. axillaris (Less.) Baker & Asteraceae & $\mathrm{P}$ & An & 6 & 20,75 & 3 & 0,61 & 0,58 & 1,5 & 2,69 & 0,90 \\
\hline Andira anthelmia (Vell.) Benth. & Fabaceae & NP & Z & 6 & 24,70 & 2 & 0,61 & 0,69 & 1 & 2,30 & 0,77 \\
\hline Chrysochlamys saldanhae (Engl.) & Clusiaceae & NP & Z & 10 & 5,69 & 2 & 1,02 & 0,16 & 1 & 2,18 & 0,73 \\
\hline Calyptranthes sp1. & Myrtaceae & NP & Z & 6 & 1,40 & 3 & 0,61 & 0,04 & 1,5 & 2,15 & 0,72 \\
\hline Annona cacans Warm. & Annonaceae & $\mathrm{P}$ & Z & 11 & 13,73 & 1 & 1,12 & 0,38 & 0,5 & 2,00 & 0,67 \\
\hline Asteraceae sp1 & Asteraceae & $\mathrm{NC}$ & $\mathrm{NC}$ & 5 & 9,02 & 2 & 0,51 & 0,25 & 1 & 1,76 & 0,59 \\
\hline Indeterminada sp1 & Indeterminada & $\mathrm{NC}$ & NC & 2 & 30,32 & 1 & 0,20 & 0,84 & 0,5 & 1,55 & 0,52 \\
\hline Myrciaria floribunda (West ex Willd.) O. Berg & Myrtaceae & NP & Z & 9 & 3,81 & 1 & 0,92 & 0,11 & 0,5 & 1,52 & 0,51 \\
\hline Alchornea sidifolia Müll.Arg. & Euphorbiaceae & $\mathrm{P}$ & Z & 2 & 7,32 & 2 & 0,20 & 0,20 & 1 & 1,41 & 0,47 \\
\hline Solanum pseudoquina A. St.-Hill. & Solanaceae & $P$ & Z & 2 & 6,70 & 2 & 0,20 & 0,19 & 1 & 1,39 & 0,46 \\
\hline Miconia cinnamomifolia (DC.) Naudin & Melastomataceae & $P$ & Z & 2 & 3,75 & 2 & 0,20 & 0,10 & 1 & 1,31 & 0,44 \\
\hline Vernonia polyanthes Less & Asteraceae & $P$ & An & 5 & 9,86 & 1 & 0,51 & 0,27 & 0,5 & 1,28 & 0,43 \\
\hline $\begin{array}{l}\text { Aniba firmula (Nees \& Mart.) Mez } \\
\text { Senna macranthera (DC. ex Collad.) H.S.Irwin \& }\end{array}$ & Lauraceae & $\mathrm{P}$ & Z & 2 & 1,07 & 2 & 0,20 & 0,03 & 1 & 1,23 & 0,41 \\
\hline Barneby & Fabaceae & $\mathrm{P}$ & $\mathrm{Au}$ & 3 & 10,98 & 1 & 0,31 & 0,31 & 0,5 & 1,11 & 0,37 \\
\hline Tibouchina arborea Cogn. & Melastomataceae & $\mathrm{P}$ & $A n$ & 4 & 7,11 & 1 & 0,41 & 0,20 & 0,5 & 1,10 & 0,37 \\
\hline Solanum leucodendron & Solanaceae & $P$ & Z & 2 & 8,17 & 1 & 0,20 & 0,23 & 0,5 & 0,93 & 0,31 \\
\hline Jacaranda micrantha Cham. & Bignoniaceae & $\mathrm{P}$ & An & 2 & 6,94 & 1 & 0,20 & 0,19 & 0,5 & 0,90 & 0,30 \\
\hline Syzygium jambos (L.) Alston & Myrtaceae & NP & Z & 1 & 5,73 & 1 & 0,10 & 0,16 & 0,5 & 0,76 & 0,25 \\
\hline Andira fraxinifolia Benth. & Fabaceae & $\mathrm{P}$ & Z & 1 & 3,80 & 1 & 0,10 & 0,11 & 0,5 & 0,71 & 0,24 \\
\hline Annona sy/vatica A.St.-Hil. & Annonaceae & NP & Z & 1 & 3,80 & 1 & 0,10 & 0,11 & 0,5 & 0,71 & 0,24 \\
\hline Guapira opposita (Vell.) Reitz & Nyctaginaceae & NP & Z & 1 & 3,14 & 1 & 0,10 & 0,09 & 0,5 & 0,69 & 0,23 \\
\hline Solanum cernuum Vell. & Solanaceae & $\mathrm{P}$ & Z & 1 & 1,54 & 1 & 0,10 & 0,04 & 0,5 & 0,64 & 0,21 \\
\hline Annona sp1 & Annonaceae & NC & Z & 1 & 0,38 & 1 & 0,10 & 0,01 & 0,5 & 0,61 & 0,20 \\
\hline Endlicheria paniculata (Spreng.) J.F.Macbr. & Lauraceae & NP & Z & 1 & 0,07 & 1 & 0,10 & 0,00 & 0,5 & 0,60 & 0,20 \\
\hline
\end{tabular}

Fonte: Elaboração dos autores. 
A espécie de quarto maior VI foi Sapium glandulosum, uma pioneira de dispersão zoocórica, decídua, heliófita ou de luz difusa. É raramente encontrada no interior de florestas semideciduais densas, exceto em florestas secundárias, localizadas em beira de rio (LORENZI, 2008). A espécie aparece em 17 parcelas do universo amostral, demonstrando boa capacidade de dispersão pela área e caráter generalista em termos de nicho.

Em quinto lugar, está Myrcia splendens, espécie generalista e frequente nos estudos da região (FONSECA; CARVALHO, 2012; SANTIAGO; CARVALHO; FONSECA, 2014; SANTANA, 2014; BRITO; CARVALHO et al., 2014).

$\mathrm{O}$ valor do índice de diversidade de Shannon foi de $\mathrm{H}^{\prime}=2,81$ nats.ind. ${ }^{-1}$ e o índice de equabilidade de Pielou foi de $\mathrm{J}^{\prime}=0,75$, próximo à maioria dos valores encontrados em fragmentos florestais estudados na região de Juiz de Fora (FONSECA; RIBEIRO; CARVALHO; 2013; SANTIAGO et al., 2014; SANTANA; CARVALHO et al., 2014;). O padrão encontrado é característico de florestas secundárias em estágios iniciais de regeneração, provavelmente em razão da atual situação da matriz, como já citado anteriormente.

\section{Grupos ecológicos}

A análise dos grupos sucessionais mostra que, em termos de densidade, a comunidade é composta principalmente por espécies pioneiras (Figura 2). 0 mesmo é visto quando se analisa a riqueza (Figura 2), demonstrando a dificuldade da área em recrutar indivíduos e espécies com características sucessionais avançadas.

A síndrome de dispersão mais ocorrente foi a zoocórica, tanto em nível de riqueza quanto de abundância (Figura 3), o que demonstra a importância do uso do fragmento pela zoofauna como corredor ecológico, constituindo-se importante local de dessedentação. De acordo com Brown e Lugo (1992) e Chazdon (2007), em florestas tropicais, as espécies zoocóricas costumam ser menos frequentes nos estágios iniciais da sucessão secundária e naquelas que sofreram maior perturbação. Esse fragmento observado, ao contrário, possui maior riqueza e densidade de espécies com essa síndrome de dispersão, não obstante esteja muito degradado. As espécies zoocóricas estão presentes em todas as parcelas analisadas e representam mais de $70 \%$ das levantadas, fato que pode estar ligado à proximidade com a água. Essa relação de zoocoria em áreas degradadas é fundamental para a sua conservação e para a aceleração do processo de restauração (MARTINS, 2009).

A grande concentração de vegetação dispersa por animais indica que esse fragmento é visitado pela fauna, o que já era de certa forma esperado, visto que o corpo hídrico presente no local serve de lugar de dessedentação da fauna dentro de uma matriz altamente impactada e seca. Há apenas outro corpo hídrico, após a linha de cumeada que separa as duas microbacias, a cerca de meio quilômetro de distância, o que justificaria, por si só, a recuperação dessa área pelo papel relevante que exerce.

Os levantamentos apresentados demonstram que, apesar de a área se encontrar em um estágio inicial de sucessão secundária, o remanescente possui grande importância na manutenção da fauna e flora local. Atua como área de conectividade e facilitação para o fluxo de dispersores e, também, como banco genético de espécies vegetais para futuros programas de manejo e restauração florestal, além de ser local da nascente de um importante córrego da região. 


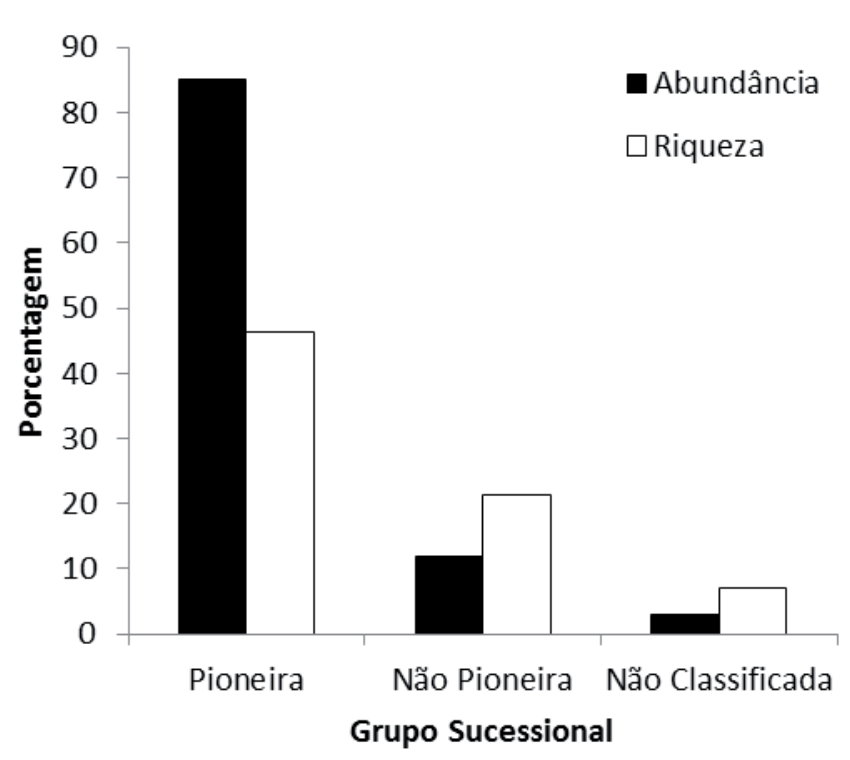

Figura 2. Distribuição da abundância e riqueza, de acordo com os grupos sucessionais. Fonte: Elaboração dos autores.

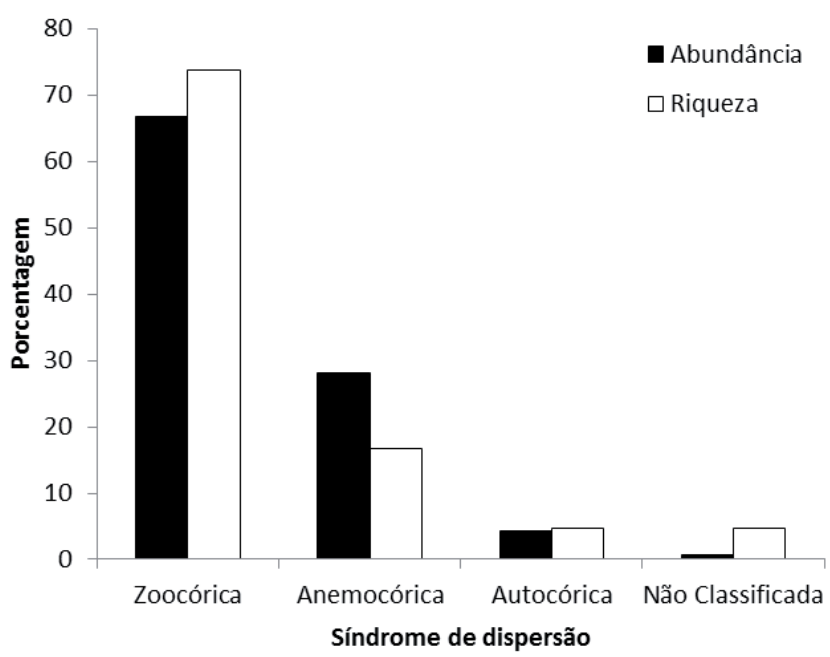

Figura 3. Distribuição da densidade das espécies segundo a síndrome de dispersão. Fonte: Elaboração dos autores.

Ainda que a sucessão na mata esteja aparentemente acontecendo, medidas de intervenção são necessárias para conservação e recuperação da área, privilegiando técnicas que a isolem dos diversos impactos, principalmente do fogo, uma prática comum no local pela população do entorno, sendo necessária a introdução de espécimes alóctones, nativas da fisionomia de Floresta Estacional Semidecidual de Montana, o enriquecimento do pool gênico e o emprego de técnicas que contemplem a recuperação do solo.

A mata ciliar possui uma dinâmica de auto sustentação, pois é a própria vegetação que dá ao solo a matéria orgânica que o compõe, mantém a umidade em níveis ótimos para que a mata ciliar se mantenha, além de proporcionar um microclima favorável ao abrigo de fauna e expansão da própria mata (JACOMINE, 2001). 


\title{
Conclusão
}

Os resultados assinalam que a comunidade se encontra em estágio inicial de sucessão secundária, conforme descrito na resolução 392/2007 - CONAMA, com baixa diversidade de espécies (H' $=2,81$ nats.ind.-1) em relação aos outros fragmentos estudados da região. A área está comprometida floristicamente em decorrência da ação de fatores antrópicos, como as constantes queimadas. Esse fato fica mais evidente pela presença de mais de 65\% de espécies pioneiras, o que demonstra a dificuldade da área em avançar para estágios sucessionais superiores. Porém, mais de $70 \%$ das espécies possuem dispersão zoocórica, o que evidencia a importância da área como um refúgio da fauna. Estudos posteriores, assim como atividades de manejo e conservação, são fundamentais, visto que se trata de uma APP de nascente e mata ciliar de um importante córrego da região.

\section{Structure and diversity of forest regeneration at the São Pedro stream headwater, Juiz de Fora, MG}

\begin{abstract}
This paper describes the floristic composition and structure of tree stratum of a woody regenerating secondary forest, the headwaters of São Pedro stream, in the rural area of Juiz de Fora, Minas Gerais, Brazil. The source was chosen because of its importance as water resource, as ecological corridor and it is located in a Permanent Preservation Area. In an excerpt comprising 700 meters from the east, 25 plots of $5 \times 5 \mathrm{~m}$ were allocated, and all individuals with diameter at breast height $(\mathrm{DBH}) \leq 5 \mathrm{~cm}$ and height> $1 \mathrm{~m}$ were sampled, totaling 983 individuals belonging to 42 species. There was a predominance of early succession stages species. It was also observed a high ecological dominance, exercised primarily by the high density of Tibouchina granulosa $(\mathrm{VI}=19.2 \%)$. The value of the index of species diversity (Shannon $\mathrm{H}^{\prime}=2.81$ nats. $^{\text {ind }}{ }^{-1}$ ) was lower than the values found in forest fragments in the region. The riparian forest fragment is small and isolated; however, it shows considerable differentiation in the arrangement of species, demonstrating the heterogeneity of tropical forests. Even though it's a small fragment within a highly impacted matrix, it has significant ecological role in the landscape in which it appears.
\end{abstract}

Key-words: Atlantic Forest. Phytosociology. Restoration ecology. Ecological corridor. Riparian forest.

\section{Referências}

APG III. An update of the Angiosperm Phylogeny Group classification for the orders and families of flowering plants: APG III. Botanical Journal of the Linnean Society, v. 161, p. 105-121, 2009.

BRASIL. Código Florestal Brasileiro. Lei n 12.651, de 25 de maio de 2012.

BRITO, P. S; CARVALHO, F. A. Estrutura e diversidade arbórea da floresta estacional semidecidual secundária no Jardim Botânico da Universidade Federal de Juiz de Fora (Juiz de Fora, MG). Rodriguesia. No prelo, 2014.

BROWN, S.; LUGO, A. E. Tropical secondary forests. Journal of Tropical Ecology, Cambridge, v.6, n.1, p.1-32, 1990. 
CARVALHO, F.A.; ABREU, R.C.R.; BARROS, K.A.R.T.; FONSECA, S.N.; SANTIAGO, D.S.; OLIVEIRA, D.E.; ASSIS, D.C.; PIMENTEL, F. O.; LYRA, M.F.B.; FURTADO, S.G. A comunidade arbórea regenerante de um 'ecossistema emergente' dominado pela espécie invasora Pinus elliottii Engelm. Interciência, v.39, n.5, p.307-312, 2014.

CARVALHO, J.O.P. Análise estrutural da regeneração natural em floresta tropical densa na região dos Tapajós no estado do Pará. 1982. Dissertação (Mestrado em Engenharia Florestal) - Universidade Federal do Paraná, Curitiba.

CHAZDON, R.L Rates of change in tree communities of secondary Neotropical forests following major disturbances. Philosophical Transactions of the Royal Society, v.362, 2007.

CONAMA. Conselho Nacional do Meio Ambiente. Resolução CONAMA n 392, de 25 de junho de 2007. Disponível em:< http://www.mma.gov.br/port/conama/legiabre.cfm?codlegi $=537>$ Acesso em: 26 nov. 2014.

DEAN, W. A Ferro e Fogo. São Paulo: Companhia das Letras, 2007.

FELFILI, J.M. Diversity, struture and dynamics of a gallery forest in central Brazil. Vegetatio. v.117, p.1-15, 1995.

FELFILI, J.M. Dynamics of the natural regeneration in the Gama gallery forest in central Brazil. Forest Ecology and Manegement. v. 91, p. 235-245, 1996.

FELFILI, J. M.; RESENDE, R. P. Conceitos e métodos em fitossociologia. Brasília: Departamento de Engenharia Florestal, Universidade de Brasília, p.64, 2003.

FELFILI, J. M.; CARVALHO, F. A.; HAIDAR, R. F. Manual para o monitoramento de parcelas permanentes nos biomas Cerrado e Pantanal. Brasília: Universidade de Brasília / Departamento de Engenharia Florestal, 2005.

FLORA DO BRASIL. Lista de espécies da flora do Brasil. Jardim Botânico do Rio de Janeiro. Disponível em: <http://floradobrasil.jbrj.gov.br/>. Acesso em 3 set. 2014.

FONSECA, C. R.; CARVALHO, F. A. Aspectos florísticos e fitossociológicos da comunidade arbórea de um fragmento urbano de floresta atlântica. Bioscience Journal, Juiz de Fora, MG, v. 28, n.5, p.820832, 2012.

FONSECA, S.N.; RIBEIRO, J.H.C.; CARVALHO, F.A. Estrutura e Diversidade da Regeneração Arbórea em uma Floresta Secundária Urbana. Floresta e Ambiente. Juiz de Fora, MG, v. 20, n. 3, p. 307-315, 2013. GOOGLE EARTH-MAPAS. http://mapas.google.com. Consulta realizada em novembro de 2012.

HAMMER, Ø.; HARPER, D. A. T.; RYAN, P. D. Paleontological Statistical. Palenteologia Eletrônica, v.4, p. 4-9, 2001.

JACOMINE, P. K. T. Solos Sob Matas Ciliares. In: RODRIGUES, R. R. ; FILHO, H. F. L. Matas Ciliares conservação e recuperação. 2.ed. São Paulo: Edusp/FAPESP, 2001.

KENT, M.; COKER, P. Vegetation description and analysis. London: John Wiley \& Sons, 1992. 
KOTTEK, M. World Map of the Köppen-Geiger climate classification updated. Meteorologische Zeitschrift. v.15, n. 3, p. 259-263, 2006.

LORENZI, H. Árvores Brasileiras: manual de identificação e cultivo de plantas arbóreas nativas do Brasil. Nova Odessa: Plantarum, 2008.

MAGURRAN, A. E. Measuring biological diversity. Oxford: Blackwell, 2004.

MACHADO, P. J.O. (Org.). Diagnóstico Físico Ambiental da Bacia Hidrográfica do Córrego São Pedro: um exercício acadêmico de gestão dos recursos hídricos. Ubá: Ed. Geographica, Consultoria, Estudos e Projetos ambientais Ltda, 2010.

MARTINS, S. V. Recuperação de Matas Ciliares. Viçosa: Aprenda Fácil, 2001.

MARTINS, S. V. Ecologia de florestas tropicais do Brasil. Viçosa: Ed.Universidade Federal de Viçosa, 2009.

OLIVEIRA-FILHO, A. T.; SCOLFORO, J. R.; SILVA, C.P.C. Compilação e caracterização das espécies arbóreas da flora nativa de Minas Gerais. In: Inventário florestal de Minas Gerais: espécies arbóreas da flora nativa. Lavras: Universidade Federal de Lavras, 2008.

OLIVEIRA-FILHO, A.T. Catálogo das árvores nativas de Minas Gerais: mapeamento e inventário da flora nativa e dos reflorestamentos de Minas Gerais. Lavras: Editora UFLA, 2006.

PMJF - Prefeitura Municipal de Juiz de Fora. Anuário Estatístico 2011. Juiz de Fora, 2011.

RAVEN, P. Biologia Vegetal. Rio de Janeiro: Guanabara Koogan, 2008.

RODRIGUES, R. R.; LEITÃO, FILHO, H. F. Matas ciliares: conservação e recuperação. 2.ed. São Paulo: USP/FAPESP, 2009.

SANTANA, L.D. Composição, diversidade e estrutura do estrato regenerante da floresta urbana do Parque Mariano Procópio (Juiz de Fora, MG). 2014. Monografia (Graduação em Ciências Biológicas). Universidade Federal de Juiz de Fora, Juiz de Fora.

SANTIAGO. D. S.; FONSECA, C. R.; CARVALHO, F. A. Regeneração natural em um fragmento florestal urbano no Jardim Botânico da Universidade Federal de Juiz de Fora ,Juiz de Fora, MG, Brasil. Revista Brasileira de Ciências Agrárias. v.9, n.1, p.117-123, 2014.

SEITZ, R.A. A análise do povoamento: o primeiro passo. Revista Floresta. v.18, n.12, p.4-11, 1988.

VANDER PIJL, L. Principles of dispersal in higher plants. 3rd ed. Berlin: Springer-Verlag, 1982.

\section{Histórico editorial}

Submetido em: 11/09/2014

Aceito em: 16/12/2014 